\title{
Selected matrix metalloproteinases activity and hypertension-mediated organ damage in relation to uric acid serum level
}

\author{
Krystian Gruszka ${ }^{1}$, Marek Rajzer ${ }^{1}$, Tomasz Drożd $\dot{z}^{1}$, Wiktoria Wojciechowska ${ }^{1}$, \\ Tomasz Pizoń ${ }^{1}$, Kamila Migacz-Gruszka ${ }^{2}$, Danuta Czarnecka ${ }^{1}$ \\ ${ }^{1} 1^{\text {st }}$ Department of Cardiology, Interventional Electrocardiology and Arterial Hypertension, \\ Jagiellonian University Medical College, Krakow, Poland \\ ${ }^{2}$ Department of Dermatology, Jagiellonian University Medical College, Krakow, Poland
}

\begin{abstract}
Background: Atherosclerosis is as a systemic inflammatory disease associated with the activation of many mediators, including matrix metalloproteinases (MMPs), and may be amplified by abnormal high serum uric acid (UA) concentration (hyperuricemia, HU). The aim of the study was to determine the relationship between serum UA concentration and activity of MMPs and their correlation with the hypertension-mediated organ damage (HMOD) intensity.

Methods: One hundred and nine patients untreated with antihypertensive, hypolipemic or uratelowering drugs with diagnosed stage 1-2 essential hypertension were included in this study. In all participants blood pressure (BP) was measured, carotid-femoral pulse wave velocity (PWV), intima-media thickness (IMT), echocardiography and blood tests including UA, lipids and serum concentrations of $\operatorname{MMPs}(1,2,3,9)$ were observed. The participants were divided into hyper-and normuricemic groups. Results: Uric acid concentration in the whole study group positively correlated with some HMOD parameters (IMT, PWV, left ventricular mass index, left atrial dimension). Among the studied metalloproteinases only MMP-3 activity positively correlated with serum UA concentration independently of age, body mass index and serum lipids $(R 2=0.11, p=0.048)$. Multivariate regression analysis showed positive association between IMT and BP, UA concentration and MMP-3 activity, independently of waist circumference and serum lipids $(R 2=0.328, p<0.002)$. Patients with HU were characterized by higher activity of MMP-3 than those without (19.41 [14.45; 21.74] vs. 13.98 [9.52; 18.97] $\mathrm{ng} / \mathrm{mL}$, $p=0.016$ ).
\end{abstract}

Conclusions: The present results may support the thesis that UA and the increased by UA activity of MMPs may take part in the development of HMOD, especially IMT. (Cardiol J 2021; 28, 6: 905-913)

Key words: arterial hypertension, uric acid, hyperuricemia, matrix metalloproteinases, metabolic syndrome

\section{Introduction}

Cardiovascular disorders caused by atherosclerosis remain the main cause of morbidity and death in developed countries. Currently atherosclerosis is defined as a systemic inflammatory disease as- sociated with the activation of many mediators and effectors, including excessive activation of matrix metalloproteinases (MMPs) [1] MMPs are a large group of zinc-dependent proteolytic enzymes which play a key role in physiological and pathological inflammatory processes, including activation of

Address for correspondence: Dr. Marek Rajzer, $1^{\text {st }}$ Department of Cardiology, Interventional Electrocardiology and Arterial Hypertension, Jagiellonian University Medical College, ul. Kopernika 17, 31-501 Kraków, Poland, tel: +48 124247300 , fax: +48 1242473 20, e-mail: rajzer37@interia.pl

Received: 21.12.2018 Accepted: 20.03.2019 Early publication date: 26.03.2019

This article is available in open access under Creative Common Attribution-Non-Commercial-No Derivatives 4.0 International (CC BY-NC-ND 4.0) license, allowing to download articles and share them with others as long as they credit the authors and the publisher, but without permission to change them in any way or use them commercially. 
immune cells, damage and apoptosis of endothelial cells, fibrosis and remodeling of vascular wall. Increased activity of MMPs was described in many inflammatory diseases as well as in selected cardiovascular diseases [2, 3].

Under physiological conditions MMPs are inhibited by a group of tissue inhibitors of metalloproteinases (TIMPs) [4, 5]. The collagenases (MMP-1, -8, -13, -18) are capable of breaking down interstitial collagen I, II, III. Collagen fragments are further degraded by gelatinases (MMP-2, -9), MMP-2, -9 are also involved in the degradation of collagen IV, vessel remodeling, angiogenesis, inflammation and atherosclerotic plaque rupture. Stromelysin-1 (MMP-3) and stromelysin-2 (MMP10) play the key role in extracellular matrix protein degradation by activation of MMPs cascade [6-8].

Essential hypertension is associated with vascular wall remodeling, which may be amplified by abnormal high serum uric acid (UA) concentration Increased UA concentration is called hyperuricemia (HU). HU is a common condition which may affect up to a quarter of the adult population [9, 10]. Many factors promote the development of HU, especially: the use of a high-purine diet, sedentary lifestyle, metabolic syndrome, obesity and arterial hypertension. In most cases, HU is accompanied by high estimated cardiovascular risk [11, 12].

Uric acid is an important antioxidant, but in excessive amounts it can activate the formation of reactive oxygen species. UA participates in atherogenesis process by enhancing inflammation, causing endothelium dysfunction, vascular smooth muscle proliferation, increased platelet adhesion and lipid peroxidation [13]. In subjects with arterial hypertension $\mathrm{HU}$ is associated with increased risk of coronary heart disease and cardiovascular mortality $[14,15]$.

The action mechanism of elevated UA concentration on the progression of vascular changes has yet to be clearly identified. Available data in the literature about the relationship between HU and MMPs activity is limited.

The aim of the study was to determine the relationship between serum UA concentration and selected MMPs activity and their correlation with hypertension-mediated organ damage (HMOD).

\section{Methods}

The study group consisted of consecutive patients with diagnosed essential hypertension stage 1 or 2 (blood pressure $[\mathrm{BP}] \geq 140 / 90$ and $<$ $<180 / 110 \mathrm{mmHg}$ ) in accordance with the $2018 \mathrm{Eu}-$ ropean Society of Hypertension/European Society of Cardiology (ESH/ESC) guidelines [16]. They were admitted within a 6 month period to the hypertension outpatient department. Subjects were both women and men aged $20-80$ years. The exclusion criteria included: symptomatic gout, coronary heart disease (previous myocardial infarction, coronary angioplasty procedure or coronary artery bypass surgery), atrial fibrillation, stroke history or transient ischemic attack episode, active acute or chronic inflammatory process, cancer, kidney or liver failure and reported treatment with antihypertensive, hypolipemic or urate-lowering drugs in the prior 4 weeks.

\section{Study procedures}

All participants underwent medical examination, with office BP measurements in standard conditions, after $10 \mathrm{~min}$ rest, in a sitting position on the non-dominant arm with the use of the Omron M5-I oscillometric device (Omron Healthcare Co., Japan). The mean of the three measurements at 1-min intervals was taken for analysis. 24-h ambulatory blood pressure monitoring (ABPM) was also performed using a SpaceLabs 90207 recorder (SpaceLabs Inc, Richmond, Washington, USA) according to ESH/ESC recommendations [16]. The SphygmoCor (AtCor Medical, Sydney, Australia) device was used to examine arterial stiffness. Carotid-femoral pulse wave velocity (PWV) and central blood pressure in the aorta were measured according to ESC expert consensus recommendations $[17,18]$. Echocardiographic examination using the Vivid $7^{\circledast}$ VingMed (GE-Healthcare Chicago, IL, USA) device was performed in accordance with the $\mathrm{ESH} / \mathrm{ESC}$ guidelines for the management of hypertension [16]. The left ventricular mass (LVM) was calculated according to the Devereaux formula using the Penn convention LVM $=1.04$ ([left ventricular internal diameter in diastole + + posterior wall thickness in diastole + interventricular septum thickness in diastole $] 3-[$ left ventricular internal diameter in diastole]3) $-13.6 \mathrm{~g}$ [19]. Ultrasound carotid arteries were examined with intima-media thickness (IMT) measurement of common carotid artery and was carried out in accordance with recommendations of the Mannheim consensus with the use of the Vivid $7^{\circledR}$ VingMed (GE-Healthcare Chicago, IL, USA) [20].

Measurements of serum concentrations of UA, creatinine, total cholesterol, high-density lipoprotein cholesterol (HDL-C), low-density lipoprotein cholesterol (LDL-C) and triglycerides were performed. Blood samples from the antecubital 
vein were taken for the determination of serum concentrations of metalloproteinases (MMP-1, MMP-2, MMP-3 and MMP-9) and tissue inhibitor of matrix metalloproteinases-1 (TIMP-1) in the morning hours before study procedures. Then the plasma was separated and samples stored at $-75^{\circ} \mathrm{C}$ until analysis. TIMP-1 plasma concentrations were measured using an ELISA kit (Human TIMP-1 Immunoassay, Quantikine, R\&D Systems Europe, Ltd. Abingdon, UK). The concentration of serum metalloproteinases was measured using kits from R\&D Systems Europe Ltd, Abingdon, UK.

According to The Third National Health and Nutrition Examination Survey (NHANES III, 1988-1994) hyperuricemia was defined as UA concentration $>7 \mathrm{mg} / \mathrm{dL}(416 \mu \mathrm{mol} / \mathrm{L})$ in men and $>5.7 \mathrm{mg} / \mathrm{dL}(339 \mu \mathrm{mol} / \mathrm{L})$ in women [21]. Based on the cut-off values, the study group was divided into hyper- and normuricemia group.

\section{Statistical analysis}

Statistical analyses were performed with STATISTICA software (StatSoft, Poland), version 13.1. Nonparametric tests were used, because some of the variables studied did not have a normal distribution and study subgroups had different numbers. Groups were compared using the Mann-Witney U test and the association between variables was studied using the Spearman rank correlation. For the evaluation of association of HMOD with UA concentration, multivariate regression analysis was used. P-values $<0.05$ were considered statistically significant.

\section{Results}

Relation of UA serum concentration with the hypertension-mediated organ damage and selected biochemical parameters

The body mass index (BMI) was 27.4 (24.3; $30.1) \mathrm{kg} / \mathrm{m}^{2}$, office systolic blood pressure (SBPoffice) was $150(135 ; 162) \mathrm{mmHg}$, office diastolic blood pressure (DBP-office) was $93(86 ; 100)$ $\mathrm{mmHg}$, heart rate (HR) was $72(66 ; 79) \mathrm{bpm}$, creatinine was $65.9(58.2 ; 74) \mu \mathrm{mol} / \mathrm{L}, \mathrm{PWV}$ was 7.8 $(7.1 ; 9.1) \mathrm{m} / \mathrm{s}$, IMT was $0.6(0.55 ; 0.75) \mathrm{mm}$, left ventricular mass index (LVMI) was 132.2 (103.9; 144) g. UA concentration in the whole study group positively correlated with: BMI, waist circumference, BP and some HMOD parameters (IMT, PWV, LVMI, left atrial dimension) and triglyceride level. UA concentration in the study group negatively correlated with HDL-C level. Among the metalloproteinases studied, only MMP-3 activity was positively correlated with UA serum concentration
(Fig. 1, Table 1). In multivariate regression analysis, after adjustment for age, BMI and serum lipids, UA associated with higher MMP-3 activity (R2 = $=0.11$, beta $=0.332, \mathrm{p}=0.048$ ) (Fig. 2 ) and PWV $(\mathrm{R} 2=0.33$, beta $=0.230, \mathrm{p}=0.0004)$, thicker IMT $(\mathrm{R} 2=0.34$, beta $=0.240, \mathrm{p}=0.04)$ and increased LVMI $(\mathrm{R} 2=0.11$, beta $=0.232, \mathrm{p}=0.0004)$.

The activity of MMP-3 correlated, like the concentration of UA, with the IMT $(r=0.292$; $\mathrm{p}=0.002)$ and the LVMI $(\mathrm{r}=0.273 ; \mathrm{p}=0.009)$.

In further analyses, both factors, MMP-3 and UA serum activity together with waist circumference, SBP and DBP obtained in 24-h ABPM and serum lipids into the multivariate regression model were used to evaluate their influence on selected parameters of HMOD.

IMT value in this model was significantly positively associated with SBP and DBP (24-h mean values in $\mathrm{ABPM})$, UA serum concentration and MMP-3 activity $(\mathrm{R} 2=0.328, \mathrm{p}<0.002)$.

Only the SBP and DBP were significant determinants of PWV $(\mathrm{R} 2=0.25, \mathrm{p}=0.0047)$.

The same multivariate regression model was not sufficient to explain LVMI variability in the group $(\mathrm{p}>0.05)$.

\section{Differences in clinical profiles of hyper- tensives with normo- or hyperuricemia}

The hyperuricemic group consisted of 21 subjects ( 15 women, 6 men). The group with normouricaemia consisted of 88 subjects ( 40 women, 48 men).

Hypertensive patients with HU were characterized by higher BMI and waist circumference in comparison to patients without HU (Table 2).

In the HU group, higher SBP during daily activity and higher SBP and DBP during night-time were observed than in the normouricemic group (Table 2).

The group with HU compared to the normouricemic group had lower HDL-C values and higher triglyceride serum concentrations (Table 3 ).

Between-group differences in activity of selected MMPs (-1, -2, -3 and -9) and TIMP-1 were analyzed. Only for MMP-3 activity was a statistically significant difference obtained. Patients with HU were characterized by higher activity of MMP-3 in relation to patients without $\mathrm{HU}$ (Table 3 ).

There were no significant differences in the prevalence of diabetes or pre-diabetic conditions between the group with $\mathrm{HU}$ and the normouricamic group.

The comparison of HMOD parameters between the present groups showed a greater IMT 


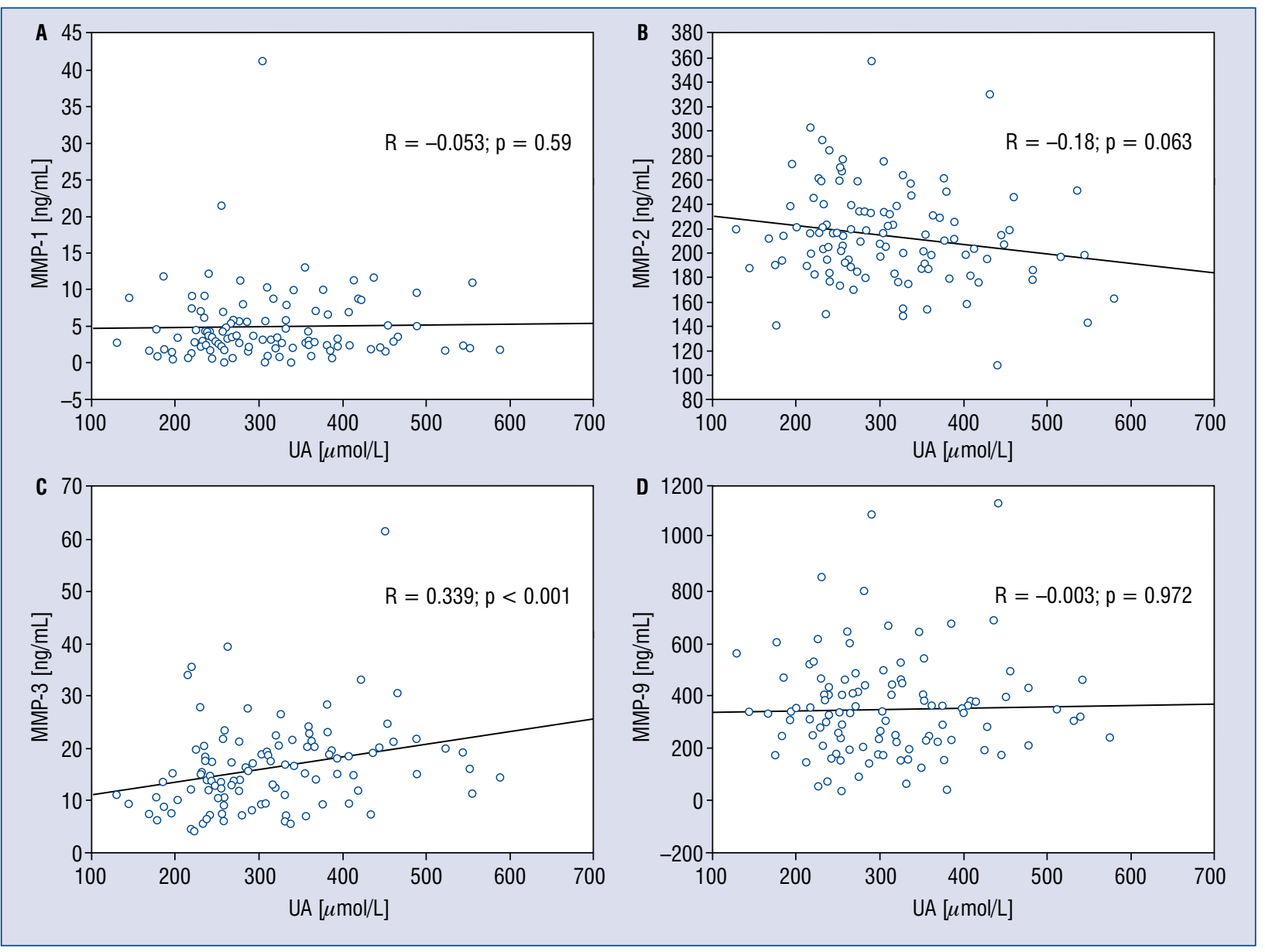

Figure 1. A-D. The relationship between selected matrix metalloproteinase (MMP-1, $-2,-3$, and -9 ) and uric acid (UA) concentration.

of the common carotid artery and larger left atrium dimension in the M-mode parasternal long axis view in the hyperuricemic group. Patients with $\mathrm{HU}$ were also characterized by higher LVM, however, this difference lost significance after indexing the body surface (LVMI). There were no significant differences between the groups examined in carotidfemoral pulse wave velocity (Table 4).

\section{Discussion}

The relationship between elevated serum UA level and arterial BP is well documented in the literature. The analysis of the Framingham Study population showed positive correlations between SBP and DBP and UA [22]. The current study also observed a positive correlation of UA concentration with systolic and diastolic office BP values. A new result in the present study was a higher $\mathrm{BP}$ at night in patients with $\mathrm{HU}$ compared to normouricemic patients.
Elevated UA serum level is often recognized as an integral component of metabolic syndrome $[23,24]$. The metabolic syndrome, as defined by the International Diabetes Federation in 2006, consists of: increased triglycerides and reduced HDL-C serum level, arterial hypertension, raised fasting plasma glucose or previously diagnosed type 2 diabetes and of course abdominal obesity [25]. The results the study herein, showed a positive correlation of most components of the metabolic syndrome with UA serum concentration. The hyperuricemic group was also characterized by: higher BMI, waist circumference, triglyceride concentration and lower serum HDL-C level. However, differences in the frequency of diabetes and pre-diabetes between normouricemic and hyperuricemic group were not observed.

The biochemical characteristics of the group with $\mathrm{HU}$ and essential hypertension in the current study was completed by higher MMP-3 activity in comparison to patients without HU. MMP-3, is a proteolytic enzyme playing a main role in the 
Table 1. The correlations of serum uric acid (UA) concentration with selected variables.

\begin{tabular}{|c|c|c|}
\hline Selected variable & $\begin{array}{l}\text { Correlation } \\
\text { coefficient (r) } \\
\text { with UA }\end{array}$ & $\mathbf{P}$ \\
\hline BMI & 0.376 & $<0.001$ \\
\hline Waist circumference & 0.486 & $<0.001$ \\
\hline SBP office & 0.104 & 0.308 \\
\hline DBP office & 0.223 & 0.027 \\
\hline 24-h SBP & 0.247 & 0.025 \\
\hline 24-h DBP & 0.238 & 0.032 \\
\hline SBP day & 0.189 & 0.051 \\
\hline DBP day & 0.256 & 0.008 \\
\hline SBP night & 0.259 & 0.008 \\
\hline DBP night & 0.264 & 0.007 \\
\hline Central BP & 0.235 & 0.016 \\
\hline IMT & 0.241 & 0.012 \\
\hline PWV & 0.203 & 0.037 \\
\hline Alx-c & -0.237 & 0.015 \\
\hline HDL-C & -0.261 & 0.006 \\
\hline Triglycerides & 0.362 & $<0.001$ \\
\hline Creatinine & 0.339 & $<0.001$ \\
\hline MMP-1 & 0.053 & 0.590 \\
\hline MMP-2 & -0.18 & 0.063 \\
\hline MMP-3 & 0.339 & $<0.001$ \\
\hline MMP-9 & -0.003 & 0.972 \\
\hline TIMP & 0.051 & 0.605 \\
\hline LVMI & 0.197 & 0.040 \\
\hline LVM & 0.376 & $<0.001$ \\
\hline LA (PLAX) & 0.487 & $<0.001$ \\
\hline
\end{tabular}

$\mathrm{BMI}$ - body mass index; SBP office - office systolic blood pressure; DBP office - office diastolic blood pressure; $24-\mathrm{h} \mathrm{SBP}-24$. -hour systolic blood pressure; 24-h DBP - 24-hour diastolic blood pressure; SBP night - systolic nighttime blood pressure; DBP night - diastolic nighttime blood pressure; SBP day - systolic blood pressure during daily activity; DBP day — diastolic blood pressure during daily activity; BP - blood pressure; ITM - intima-media thickness; PWV - pulse wave velocity; Alx-c - central augmentation index; HDL-C - high density lipoprotein cholesterol; MMP-1, -2, -3, -9 - matrix metalloproteinase 1, 2, 3, 9; TIMP tissue inhibitor of metalloproteinases; LVMI - left ventricular mass index; LVM - left ventricular mass, LA — left atrium dimension in PLAX presentation

activation of other MMPs. The cascade of MMPs is responsible for the degradation of collagen and other fibrile proteins, leading to the remodeling of vascular wall, formation and destabilization of atherosclerotic plaque [26, 27].

In many diseases, MMPs are over-expressed and their over-activity leads to pathological heart and vessel remodeling, and the development of cardiovascular diseases [7, 28]. Increased activity of MMP-1, $-2,-3$ and -9 might also be associated

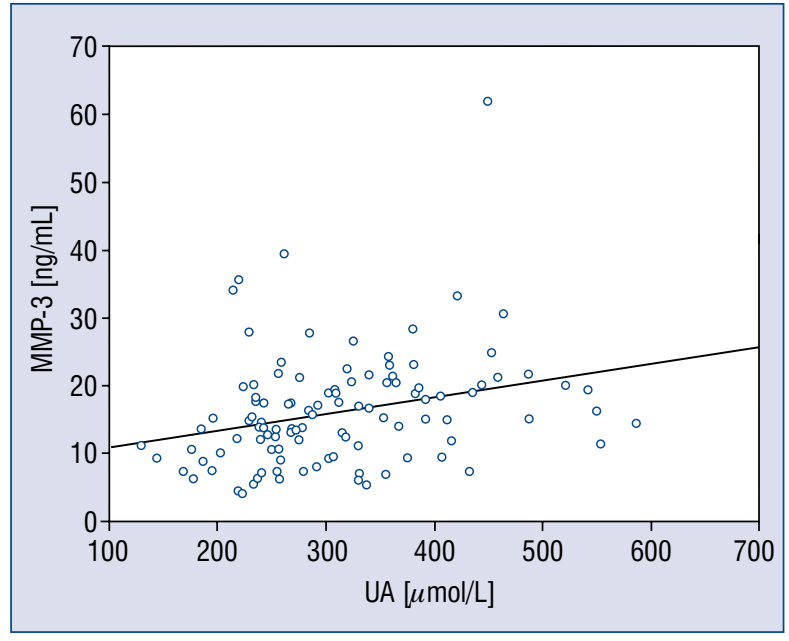

Figure 2. Association between matrix metalloproteinase 3 (MMP-3) and uric acid (UA) serum levels after adjustment to: age, waist circumference, total cholesterol, low density lipoprotein cholesterol, high density lipoprotein cholesterol and triglycerides serum concentration. Uric acid $=0.278 \times$ MMP $-3+259.9$.

with a higher risk of death independently of other typical cardiovascular risk factors [29].

The most important result of the present study is a strong, independent association between increased activity of MMP-3 UA serum concentration in patients with mild to moderate essential arterial hypertension. The data about the association of MMP-3 activity and UA concentration in the literature is limited and includes subjects with inflammatory diseases. Increased activity of MMP-3 has been reported in gout and acute arthritis [30, 31]. In patients with lupus erythematosus a positive correlation of plasma MMP-3 and UA concentration was observed. The latter is similar to present results obtained in patients with essential arterial hypertension free of acute or chronic inflammatory diseases [32]. A positive relationship between plasma activity of collagenase-2 (MMP-2) and UA concentration in men with coronary artery disease was reported $[33,34]$. Tan et al. [35] showed that higher activity of MMP-9 coexists with higher concentrations of UA and higher IMT. In opposition to the abovementioned results in an experimental animal study performed in rats showed that UA-induced inflammation led to a decrease in MMP-9 activity [36]. Similarly, UA administration during acute phase of ischemic stroke decreased the activity of proinflammatory MMP-9 [37]. In the present study MMP-2 and MMP-9 activity did not show a significant association with UA level or HMOD parameters. 
Table 2. Groups characteristics. Anthropometric and clinical data.

\begin{tabular}{lccc}
\hline Selected variable & $\begin{array}{c}\text { Hyperuricemic group } \\
(\mathbf{n}=21)\end{array}$ & $\begin{array}{c}\text { Normouricemic group } \\
(\mathbf{n}=88)\end{array}$ & $\begin{array}{c}\text { P } \\
\text { (the Mann-Whitney U test) }\end{array}$ \\
\hline Age [years] & $52(43 ; 60)$ & $54(42 ; 61)$ & $\mathbf{0 . 0 3 0}$ \\
Sex (no. of females) & $15(71.4 \%)$ & $40(45.5 \%)$ & 0.803 \\
Weight [kg] & $88(84 ; 95)$ & $75(65 ; 86)$ & $\mathbf{0 . 0 0 1}$ \\
Haight [cm] & $172(170 ; 176)$ & $169(162 ; 176)$ & 0.1477 \\
BMI [kg/m²] & $30.08(28.4 ; 33.53)$ & $26.8(23.85 ; 29 ; 48)$ & $<\mathbf{0 . 0 0 1}$ \\
Waist circumference [cm] & $99(92 ; 106)$ & $90(81 ; 97)$ & 0.001 \\
Heart rate $[\mathrm{bpm}]$ & $70(64 ; 75)$ & $72(67 ; 80)$ & 0.203 \\
SBP office $[\mathrm{mmHg}]$ & $155(140 ; 178)$ & $150(135 ; 161)$ & 0.176 \\
DBP office $[\mathrm{mmHg}]$ & $94(90 ; 109)$ & $92(85 ; 99)$ & 0.073 \\
24h SBP [mmHg] & $134(123 ; 138)$ & $128(120 ; 132)$ & 0.070 \\
24h DBP [mmHg] & $82(76 ; 87)$ & $77(72 ; 84)$ & 0.118 \\
SBP day [mmHg] & $136(125 ; 140)$ & $126(119 ; 133)$ & $\mathbf{0 . 0 1 5}$ \\
DBP day [mmHg] & $83(77 ; 89)$ & $80(74 ; 85)$ & 0.092 \\
SBP night $[\mathrm{mmHg}]$ & $119(112 ; 129)$ & $114(107 ; 121)$ & $\mathbf{0 . 0 1 6}$ \\
DBP night $[\mathrm{mmHg}]$ & $73(67 ; 77)$ & $68(62 ; 73)$ & $\mathbf{0 . 0 2 2}$ \\
\hline
\end{tabular}

Values presented as medians (interquartiles ranges) or numbers (part of the group in \%). Abbreviations — see Table 1.

Table 3. Group characteristics. Biochemical blood tests.

\begin{tabular}{lccc}
\hline Selected variable & $\begin{array}{c}\text { Hyperuricemic group } \\
(\mathbf{n}=21)\end{array}$ & $\begin{array}{c}\text { Normouricemic group } \\
(\mathbf{n}=88)\end{array}$ & $\begin{array}{c}\mathbf{P} \\
\text { (the Mann-Whitney U test) }\end{array}$ \\
\hline Uric acid $[\mu \mathrm{mol} / \mathrm{L}]$ & $449(416 ; 487)$ & $268(235 ; 324)$ & $<\mathbf{0 . 0 0 1}$ \\
MMP-1 $[\mathrm{ng} / \mathrm{mL}]$ & $3.51(2.13 ; 8.64)$ & $3.43(1.99 ; 5.76)$ & 0.350 \\
MMP-2 $[\mathrm{ng} / \mathrm{mL}]$ & $203.8(186.2 ; 218.8)$ & $214.7(189 ; 239.4)$ & 0.233 \\
MMP-3 $[\mathrm{ng} / \mathrm{mL}]$ & $19.41(14.45 ; 21.74)$ & $13.98(9.52 ; 18.97)$ & $\mathbf{0 . 0 1 6}$ \\
MMP-9 $[\mathrm{ng} / \mathrm{mL}]$ & $350.1(245.1 ; 432.3)$ & $335.6(209.9 ; 442.9)$ & 0.417 \\
TIMP $[\mathrm{ng} / \mathrm{mL}]$ & $92.9(81.2 ; 106.8)$ & $86.8(80 ; 101.3)$ & 0.335 \\
Creatinine $[\mu \mathrm{mol} / \mathrm{L}]$ & $68.9(64.2 ; 78.9)$ & $65.15(57.65 ; 72.55)$ & $\mathbf{0 . 0 2 7}$ \\
Urea $[\mathrm{mmol} / \mathrm{L}]$ & $6.1(5.2 ; 6.8)$ & $5.5(4.55 ; 6.3)$ & 0.0739 \\
Total cholesterol $[\mathrm{mmol} / \mathrm{L}]$ & $5.43(4.87 ; 5.99)$ & $5.27(4.57 ; 6.08)$ & 0.563 \\
LDL-C $[\mathrm{mmol} / \mathrm{L}]$ & $3(2.71 ; 3.86)$ & $3.21(2.44 ; 3.75)$ & 0.482 \\
HDL-C $[\mathrm{mmol} / \mathrm{L}]$ & $1.17(1.09 ; 1.5)$ & $1.44(1.19 ; 1.7)$ & $\mathbf{0 . 0 2 9}$ \\
Triglycerides $[\mathrm{mmol} / \mathrm{L}]$ & $1.56(1.16 ; 2.18)$ & $1.2(0.94 ; 1.57)$ & $\mathbf{0 . 0 1 8}$ \\
\hline
\end{tabular}

Values presented as medians (interquartiles ranges). LDL-C — low density lipoprotein cholesterol; other abbreviations — see Table 1.

Lien et al. [38] studied various plasma metalloproteinase activity in atherosclerosis. Only increased MMP-3 activity showed a significant relationship with the degree of atherosclerosis in the carotid arteries. A similar result was obtained in our study. The severity of atherosclerosis in carotid arteries evaluated by IMT was related to UA and MMP-3 concentrations. Kawamoto et al. [39] showed that UA in men may increase carotid atherosclerosis independent of other factors. The authors concluded that people with hypertension and hyperuricemia are characterized by greater IMT than hypertensive patients without HU. Increased IMT in this study correlated with UA concentration independently of the BP level. Hyperuricemia may also negatively affect other HMOD indicators [40]. In a population of more than 4,000 healthy participants selected from the Generation 3 Framing- 
Table 4. Selected hypertension-mediated organ damage (HMOD).

\begin{tabular}{lccc}
\hline Selected HMOD & $\begin{array}{c}\text { Hyperuricemic group } \\
(\mathbf{n}=\mathbf{2 1})\end{array}$ & $\begin{array}{c}\text { Normouricemic group } \\
(\mathbf{n}=88)\end{array}$ & $\begin{array}{c}\text { P } \\
\text { (the Mann-Whitney U test) }\end{array}$ \\
\hline LVMI [g/m²] & $129.32(114.72 ; 156.53)$ & $123.1(102.03 ; 138.93)$ & 0.145 \\
LVM [g] & $268.62(220.77 ; 331.19)$ & $226.41(185.76 ; 261.6)$ & $\mathbf{0 . 0 0 6}$ \\
LA (PLAX) [mm] & $45(42 ; 46)$ & $40(36 ; 43)$ & $<\mathbf{0 . 0 0 1}$ \\
IMT [mm] & $0.65(0.6 ; 0.8)$ & $0.6(0.5 ; 0.75)$ & $\mathbf{0 . 0 3 8}$ \\
PWV [m/s] & $8.4(7.4 ; 8.9)$ & $7.7(7.1 ; 9.2)$ & 0.258 \\
C-Alx [\%] & $24(14 ; 29)$ & $25(14 ; 33)$ & 0.524 \\
eGFR [mL/min/1.73 $\left.\mathrm{m}^{2}\right]$ & $95(82 ; 109)$ & $97.5(86 ; 108)$ & 0.514 \\
\hline
\end{tabular}

Values presented as medians (interquartiles ranges). LVMI — left ventricular mass index; LVM — left ventricular mass; LA — left atrium dimension in PLAX presentation; IMT — intima-media thickness; PWV — pulse wave velocity, c-Alx - central augmentation index; eGFR - estimated glomerular filtration rate

ham cohort, an independent positive relationship between UA level and carotid-femoral PWV was proved [41]. In a much smaller study, carried out with a group of 222 subjects with essential hypertension, a positive correlation of PWV with UA in hypertensive patients was also observed [42]. In the current study, the group of patients with essential hypertension showed a positive correlation of arterial stiffness (evaluated by carotid-femoral PWV) with UA concentration.

There are existing reports in the literature indicating that UA serum concentration is associated with decreased left ventricular function and left ventricle hypertrophy $[43,44]$. In the patients of this study a positive correlation was observed between UA and LVMI and UA and the left atrium dimension. Similar results have been described by Tavil et al. [45]. The current study also performed a multivariate regression analysis of the simultaneous effect of UA and MMP-3 concentrations on the other HMODs. Analysis for LVMI did not show statistical significance. In the case of PWV, $\mathrm{BP}$ values played the main role, and the effects of UA and MMP-3 were not significant.

Based on these results and data from the literature, it was suspected that among different indicators of HMOD (except for) hypertension there are big differences in factors determining their development and advancement. IMT is the HMOD most closely reflecting atherosclerosis; in the present study it was associated with proinflammatory factors like UA concentration and MMP-3 activity. Results obtained herein may support the thesis that UA and increased by UA activity of MMPs may take part in the development of HMOD, especially IMT. These results are consistent with the inflammatory and free radicals hypothesis of UA side effects.
However UA may play both pro- and antioxidative roles, depending on its concentration, solubility and place of action (plasma or cells) [46], free radicals formed in various mechanisms in hyperuricemia [47] have a great potential to activate various inflammatory mechanisms, including the activation of metalloproteinases cascade [48].

\section{Conclusions}

In patients with primary arterial hypertension UA concentration is associated with higher MMP-3 serum activity and selected hypertension-mediated organ damage advancement, especially carotid IMT. Patients with $\mathrm{HU}$ and arterial hypertension are characterized by a symptom cluster typical for metabolic syndrome and more advanced structural changes in the heart and vessels as well as higher activity of MMP-3.

\section{Funding}

This study was supported by the Polish Ministry of Science and Higher Education grant No. NN402367333.

\section{Conflict of interest: None declared}

\section{Reference}

1. Galis ZS, Khatri JJ. Matrix metalloproteinases in vascular remodeling and atherogenesis: the good, the bad, and the ugly. Circ Res. 2002; 90(3): 251-262, indexed in Pubmed: 11861412.

2. Matsuyama A, Sakai N, Ishigami M, et al. Matrix metalloproteinases as novel disease markers in Takayasu arteritis. Circulation. 2003; 108(12): 1469-1473, doi: 10.1161/01.CIR.000 0090689.69973.B1, indexed in Pubmed: 12952836.

3. Vitlianova K, Georgieva J, Milanova M, et al. Blood pressure control predicts plasma matrix metalloproteinase- 9 in diabetes mellitus type II. Arch Med Sci. 2015; 11(1): 85-91, doi: 10.5114/ aoms.2015.49208, indexed in Pubmed: 25861293. 
4. Visse R, Nagase H. Matrix metalloproteinases and tissue inhibitors of metalloproteinases: structure, function, and biochemistry. Circ Res. 2003; 92(8): 827-839, doi: 10.1161/01. RES.0000070112.80711.3D, indexed in Pubmed: 12730128.

5. Johnson JL. Matrix metalloproteinases: influence on smooth muscle cells and atherosclerotic plaque stability. Expert Rev Cardiovasc Ther. 2007; 5(2): 265-282, doi: 10.1586/14779072.5.2.265, indexed in Pubmed: 17338671.

6. Johnson J. Metalloproteinases in atherosclerosis. Eur J Pharmacol. 2017; 816: 93-106, doi: 10.1016/j.ejphar.2017.09.007.

7. Raffetto J, Khalil R. Matrix metalloproteinases and their inhibitors in vascular remodeling and vascular disease. Biochem Pharmacol. 2008; 75(2): 346-359, doi: 10.1016/j.bcp.2007.07.004.

8. Jaiswal A, Chhabra A, Malhotra U, et al. Comparative analysis of human matrix metalloproteinases: Emerging therapeutic targets in diseases. Bioinformation. 2011; 6(1): 23-30, indexed in Pubmed: 21464841.

9. Zhu Y, Pandya BJ, Choi HK. Prevalence of gout and hyperuricemia in the US general population: the National Health and Nutrition Examination Survey 2007-2008. Arthritis Rheum. 2011; 63(10): 3136-3141, doi: 10.1002/art.30520, indexed in Pubmed: 21800283.

10. Kumar A U A, Browne LD, Li X, et al. Temporal trends in hyperuricaemia in the Irish health system from 2006-2014: A cohort study. PLoS One. 2018; 13(5): e0198197, doi: 10.1371/journal. pone.0198197, indexed in Pubmed: 29852506.

11. Thiele P, Schröder HE. Epidemiology of hyperuricemia and gout. Z Gesamte Inn Med. 1982; 37(13): 406-410.

12. Abeles AM. Hyperuricemia, gout, and cardiovascular disease: an update. Curr Rheumatol Rep. 2015; 17(3): 13, doi: 10.1007/ s11926-015-0495-2, indexed in Pubmed: 25740704.

13. Johnson RJ, Kang DH, Feig D, et al. Is there a pathogenetic role for uric acid in hypertension and cardiovascular and renal disease? Hypertension. 2003; 41(6): 1183-1190, doi: 10.1161/01. HYP.0000069700.62727.C5, indexed in Pubmed: 12707287.

14. Li M, Hu X, Fan Y, et al. Hyperuricemia and the risk for coronary heart disease morbidity and mortality a systematic review and dose-response meta-analysis. Sci Rep. 2016; 6: 19520, doi: 10.1038/srep19520, indexed in Pubmed: 26814153.

15. Qin T, Zhou X, Wang Ji, et al. Hyperuricemia and the Prognosis of Hypertensive Patients: A Systematic Review and Meta-Analysis. J Clin Hypertens (Greenwich). 2016; 18(12): 1268-1278, doi: 10.1111/jch.12855, indexed in Pubmed: 27247021.

16. Williams B, Mancia G, Spiering W, et al. 2018 ESC/ESH Guidelines for the management of arterial hypertension. J Hypertens. 2018; 36(10): 1953-2041, doi: 10.1097/hjh.0000000000001940.

17. Laurent S, Cockcroft J, Bortel LV, et al. Expert consensus document on arterial stiffness: methodological issues and clinical applications. European Heart Journal. 2006; 27(21): 2588-2605, doi: 10.1093/eurheartj/ehl254.

18. Van Bortel LM, Laurent S, Boutouyrie P, et al. Expert consensus document on the measurement of aortic stiffness in daily practice using carotid-femoral pulse wave velocity. J Hypertens. 2012; 30(3): 445-448, doi: 10.1097/hjh.0b013e32834fa8b0.

19. Devereux RB, Reichek N. Echocardiographic determination of left ventricular mass in man. Anatomic validation of the method. Circulation. 1977; 55(4): 613-618, indexed in Pubmed: 138494.

20. Touboul PJ, Hennerici MG, Meairs S, et al. Mannheim Carotid Intima-Media Thickness and Plaque Consensus (2004-2006-2011). Cerebrovasc Dis. 2012; 34(4): 290-296, doi: 10.1159/000343145.

21. Gunter EW, Lewis BG, Koncikowski SM. Laboratory procedures used for the Third National Health and Nutrition Examination
Survey (NHANES III), 1988-1994. U.S. Department Of Health And Human Services. 1996. .https://www.cdc.gov/nchs/data/ nhanes/nhanes3/cdrom/nchs/manuals/labman.pdf.

22. Sundström J, Sullivan L, D'Agostino RB, et al. Relations of serum uric acid to longitudinal blood pressure tracking and hypertension incidence. Hypertension. 2005; 45(1): 28-33, doi: 10.1161/01. HYP.0000150784.92944.9a, indexed in Pubmed: 15569852.

23. Silva HA, Carraro JC, Bressan J, et al. Relation between uric acid and metabolic syndrome in subjects with cardiometabolic risk. Einstein (Sao Paulo). 2015; 13(2): 202-208, doi: 10.1590/S167945082015A03194, indexed in Pubmed: 26018145.

24. Wang H, Zhang H, Sun L, et al. Roles of hyperuricemia in metabolic syndrome and cardiac-kidney-vascular system diseases. Am J Transl Res. 2018; 10(9): 2749-2763, indexed in Pubmed: 30323864.

25. Alberti KG, Zimmet P, Shaw J. Metabolic syndrome--a new world-wide definition. A Consensus Statement from the International Diabetes Federation. Diabet Med. 2006; 23(5): 469-480, doi: 10.1111/j.14645491.2006.01858.x, indexed in Pubmed: 16681555.

26. Woessner JF. Matrix metalloproteinases and their inhibitors in connective tissue remodeling. FASEB J. 1991; 5(8): 2145-2154, indexed in Pubmed:1850705.

27. Ye S. Influence of matrix metalloproteinase genotype on cardiovascular disease susceptibility and outcome. Cardiovasc Res. 2006; 69(3): 636-645, doi: 10.1016/j.cardiores.2005.07.015, indexed in Pubmed: 16122719.

28. Heagerty AM, Aalkjaer C, Bund SJ, et al. Small artery structure in hypertension. Dual processes of remodeling and growth. Hypertension. 1993; 21(4): 391-397, indexed in Pubmed: 8458640 .

29. Peeters SA, Engelen L, Buijs J, et al. Plasma matrix metalloproteinases are associated with incident cardiovascular disease and all-cause mortality in patients with type 1 diabetes: a 12 -year follow-up study. Cardiovasc Diabetol. 2017; 16(1): 55, doi: 10.1186/ s12933-017-0539-1, indexed in Pubmed:28446168.

30. Zucker S, Lysik RM, Zarrabi MH, et al. Elevated plasma stromelysin levels in arthritis. J Rheumatol. 1994; 21(12): 2329-2333, indexed in Pubmed:7699637.

31. Ribbens C, Martin y Porras M, Franchimont N, et al. Increased matrix metalloproteinase-3 serum levels in rheumatic diseases: relationship with synovitis and steroid treatment. Ann Rheum Dis. 2002; 61(2): 161-166, indexed in Pubmed: 11796404.

32. Kotajima L, Aotsuka S, Fujimani M, et al. Increased levels of matrix metalloproteinase-3 in sera from patients with active lupus nephritis. Clin Exp Rheumatol. 1998; 16(4): 409-415, indexed in Pubmed: 9706420.

33. Leyva F. Uric acid in chronic heart failure: a marker of chronic inflammation. Eur Heart J. 1998; 19(12): 1814-1822, doi: 10.1053/ euhj.1998.1188.

34. Wingrove CS, Garr ED, Leyva F, et al. Elevated circulating matrix metalloproteinase-2 in coronary heart disease (abstr). Eur Hear J Abstr. 1998; 19(Suppl. ): 613.

35. Tan C, Liu Yi, Li W, et al. Associations of matrix metalloproteinase-9 and monocyte chemoattractant protein- 1 concentrations with carotid atherosclerosis, based on measurements of plaque and intima-media thickness. Atherosclerosis. 2014; 232(1): 199-203, doi:10.1016/j.atherosclerosis.2013.11.040, indexed in Pubmed: 24401238.

36. Wang Y, Guo W, Li Y, et al. Hypothermia induced by adenosine 5'-monophosphate attenuates injury in an L-arginine-induced acute pancreatitis rat model. J Gastroenterol Hepatol. 2014; 29(4): 742-748, doi: 10.1111/jgh.12448, indexed in Pubmed: 24224980 . 
37. Amaro S, Obach V, Cervera A, et al. Course of matrix metalloproteinase- 9 isoforms after the administration of uric acid in patients with acute stroke. J Neurol. 2009; 256(4): 651-656, doi: 10.1007/ s00415-009-0153-6.

38. Lien LM, Hsieh YC, Bai CH, et al. Association of blood active matrix metalloproteinase-3 with carotid plaque score from a community population in Taiwan. Atherosclerosis. 2010; 212(2): 595-600, doi: 10.1016/j.atherosclerosis.2010.05.040, indexed in Pubmed: 20609440.

39. Kawamoto R, Tomita H, Oka Y, et al. Relationship between serum uric acid concentration, metabolic syndrome and carotid atherosclerosis. Intern Med. 2006; 45(9): 605-614, indexed in Pubmed: 16755091.

40. Li Y, Lu J, Wu X, et al. Serum uric acid concentration and asymptomatic hyperuricemia with subclinical organ damage in general population. Angiology. 2014; 65(7): 634-640, doi: 10.1177/0003319713513143, indexed in Pubmed: 24327770.

41. Mehta T, Nuccio E, McFann K, et al. Association of Uric Acid With Vascular Stiffness in the Framingham Heart Study. Am J Hypertens. 2015; 28(7): 877-883, doi: 10.1093/ajh/hpu253, indexed in Pubmed: 25552515.

42. Mulè G, Riccobene R, Castiglia $\mathrm{A}$, et al. Relationships between mild hyperuricaemia and aortic stiffness in untreated hypertensive patients. Nutr Metab Cardiovasc Dis. 2014; 24(7): 744-750, doi: 10.1016/j.numecd.2014.01.014, indexed in Pubmed: 24675008.
43. Fang X, Pan C, Chen Y, et al. Assessment of subclinical left ventricular changes in essential hypertensive patients with hyperuricemia: A three-dimensional speckle-tracking echocardiography study. Clin Exp Hypertens. 2017; 39(1): 93-99, doi: 10.108 0/10641963.2016.1210626, indexed in Pubmed: 28072551.

44. Krishnan E, Hariri A, Dabbous O, et al. Hyperuricemia and the echocardiographic measures of myocardial dysfunction. Congest Heart Fail. 2012; 18(3): 138-143, doi: 10.1111/j.17517133.2011.00259.x, indexed in Pubmed: 22587743.

45. Tavil Y, Kaya MG, Oktar SO, et al. Uric acid level and its association with carotid intima-media thickness in patients with hypertension. Atherosclerosis. 2008; 197(1): 159-163, doi: 10.1016/j. atherosclerosis.2007.03.008, indexed in Pubmed: 17416371.

46. Sautin YY, Johnson RJ. Uric acid: the oxidant-antioxidant paradox. Nucleosides Nucleotides Nucleic Acids. 2008; 27(6): 608-619, doi:10.1080/15257770802138558, indexed in Pubmed: 18600514.

47. Pasalic D, Marinkovic N, Feher-Turkovic L. Uric acid as one of the important factors in multifactorial disorders--facts and controversies. Biochem Med (Zagreb). 2012; 22(1): 63-75, indexed in Pubmed: 22384520.

48. Rajagopalan S, Meng XP, Ramasamy S, et al. Reactive oxygen species produced by macrophage-derived foam cells regulate the activity of vascular matrix metalloproteinases in vitro. Implications for atherosclerotic plaque stability. J Clin Invest. 1996; 98(11): 2572-2579, doi: 10.1172/JCI119076, indexed in Pubmed: 8958220. 